\title{
Conceptual design and optimization of self microemulsifying drug delivery systems for dapsone by using Box-Behnken design
}

\author{
Jayashri MAHORE ${ }^{1 *}$ (D), Aniket SHELAR ${ }^{1}$ (D), Sanjeevani DESHKAR ${ }^{1}$ (D), Ghansham MORE ${ }^{1}$ \\ 1 Department of Pharmaceutics, Dr. D. Y. Patil Institute of Pharmaceutical Sciences and Research, Pimpri, Pune, \\ Maharashtra, India. \\ * Corresponding Author. E-mail: jayashri.mahore@dypvp.edu.in (J.M.); Tel. +91-202-742 0026
}

Received: 02 November 2020 / Revised: 02 February 2021 / Accepted: 09 February 2021

\begin{abstract}
Dapsone is a class II BCS with antibacterial and anti-inflammatory action. The goal of this study was to devise a dapsone (DP) system of solid self-microemulsifying drug delivery (S-SMEDDS). Various proportions of capryol 90 as an oil form, tween 80 as a surfactant and Labrasol as a co-surfactant were selected to prepare a pseudo ternary diagram for the self-microemulsifying drug delivery system (L-SMEDDS). The optimized formulation of LSMEDDS (F8) containing capryol $90(10$ percent w/w), Tween $80(67.5 / 5 \mathrm{w} / \mathrm{w})$, and labrasol $(22.5$ percent w/w) showed the smallest particle size, less emulsification time, high optical clarity, in-vitro release and improved ex-vivo permeation. L-SMEDDDS was converted to S-SMEDDS by adsorbing on neusilin US2 and spray drying with aerosil 200. The effect of inlet temperature (A), feed flow rate (B) and carrier concentration (C) on particle size (Y1) and \% practical yield (Y2) was studied using Box-Behnken design. Using the results of dependent variables, polynomial equations, surface response plots, and contour plots were developed. S-SMEDDS have been tested for flow properties, drug quality, reconstitution properties, DSC, XRD, SEM, drug release in vitro and anti-inflammatory activity in vivo. The present study showed the applicability of design of experiments (DOE) to optimize the process parameters needed to produce DP S-SMEDDS as an effective approach to improving its solubility.
\end{abstract}

KEYWORDS: Self micro-emulsifying drug delivery system; labrasol; capryol 90; Box-Behnken design; neusilin US2.

\section{INTRODUCTION}

While a drug can be administered in many ways, the oral route has been preferred by almost every patient as a major, economical, easiest, and obvious route of administration. Nearly $40-70 \%$ of all new chemical entities that join the drug production programs have inadequate aqueous solubility resulting in low bioavailability, high intra-subject and inter-subject variability, loss of dosage, degradation of gastric and enzymatic products. Lipid-based formulations have demonstrated success in enhancing the oral bioavailability of poorly water-soluble drugs [1]. Pouton (2006) [2] has classified the lipid fomulation classification system (LFCS) into four classes namely; type I, II, IIIA, IIIB and IV. In this LFCS, selfemulsifying drug delivery system (SEDDS) forms a not clear emulsion with droplet size in the range of 100$300 \mathrm{~nm}$ while self-emulsifying drug delivery system (SMEDDS) displays a clear microemulsion with droplet size of $>50 \mathrm{~nm}$ [3].

SMEDDS emulsify rapidly in gastrointestinal fluids and under gentle agitation. Small size droplets produced due to the process of spontaneous emulsification reflect the drug in solubilized form. The presence of lipids changes the pattern of drug absorption and causes bioavailability to rise [4]. The selection of suitable ingredients for SMEDDS formulation is based on; solubility of the drug in oil, surfactant, and cosurfactant; maximum self-emulsification area obtained with the selected oil, surfactant, co-surfactant and final droplet size distribution of the resulting emulsion in phase diagram [5]]. The interaction of liquid SMEDDS with capsule shell and the precipitation of active ingredients at lower temperatures makes it important to transform liquid SMEDDS into solid SMEDDS to resolve the problems [6]. Conversion of the liquid SMEDDS (L-SMEDDS) to solid SMEDDS (S-SMEDDS) involves adsorption to solid carriers such as colloidal silica dextran, neusiline UFL2, neusiline US2 [7]. The methods used include spray drying, freeze-

How to cite this article: Mahore J, Shelar A, Deshkar S, More G. Design and development of self-microemulsifying drug delivery systems for dapsone by using Box-Behnken design. J Res Pharm. 2021; 25(2): 179-195. 
drying, rotary evaporation, extrusion-spheronization melting, and granulation melting. Dapsone (DP) incorporates both antimicrobial/antiprotozoal properties resembling those of non-steroidal antiinflammatory drugs [8]. This is a valuable leprosy treatment drug used to treat leprosy caused by Mycobacterium leprae that affects the skin, eyes, and nerves, causing skin lesions, eye pain, vision loss, weakness, and numbness [9].

DP is a category II Biopharmaceutical Classification System (BCS), with low water solubility with 0.97 $\log$ P. The low solubility of DP ( 1 in 7000 of water) results in poor bioavailability and despite of therapeutic potential, low solubility can cause microbial resistance. Researchers have attempted to improve the permeability of DP provided by topical treatment routes (topical micro emulsion-based gel [10], topical solid lipid nanoparticles based gel [11], topical liposome [12], etc.) There are tablets with DP (100 mg) available for oral administration. A viable alternative dosage form is needed which will be able to keep postadministration of the drug in a soluble state and can also limit side effects by reducing the dose of DP.

Thus DP's S-SMEDDS was developed using Box-Behnken Model (BBD) in the present analysis. DP is available in different doses $(25 \mathrm{mg}, 50 \mathrm{mg}$, and $100 \mathrm{mg}$ ); as the working dose, we have restricted it to $25 \mathrm{mg}$ to restrict the total volume of the formulation. BBD is used as a dependent factor to analyze the relationship between one or more variables of response [13]. BBD usually needs three independent factors that have three levels. BBD needs a few experimental runs, which are considered more effective than central composite design and complete factorial designs. BBD does not involve combinations for which all variables are at their maximum or lowest levels simultaneously, the experiments performed under extreme conditions that often offer unsatisfactory results could be avoided [14]. Optimized S-SMEDDS has been characterized by scanning electron microscope (SEM), differential calorimetry scanning (DSC), and X-ray diffraction.

\section{RESULTS AND DISCUSSION}

\subsection{Saturation solubility of DP}

Dapson is a Class II BCS drug and has very less water-solubility. DP's saturation solubility was found to be $0.24 \pm 0.056 \mathrm{mg} / \mathrm{mL}$ in distilled water, and $49.76 \pm 0.68 \mathrm{mg} / \mathrm{mL}$ in methanol.

\subsection{The solubility of DP in different vehicles}

Self-emulsifying drug delivery system components should have a high solubilizing capacity for the drug which can ensure that the drug is solubilized in the resulting dispersion. Appropriate oil, surfactant, and co-surfactant selection can prevent precipitation of the drug on in vivo gut lumen dilution [15]. Results from the solubility tests are shown in Table 1. We picked capryol 90 (oil), tween 80 (surfactant with a value of 15.0), and labrasol (cosurfactants) for our analysis.

\subsection{Screening of surfactants and co-surfactants}

Surfactant selection is very critical, as it induces gastric irritation. Due to its lower irritation potential and lower critical micelle concentration values, non-ionic surfactants are favored over ionic surfactant [16].

Interfacial energy decreased as surfactant and co-surfactant gets adsorbed on interface. The reduction in the free energy needed for the formation of emulsions enhances the formulation's thermodynamic stability [17]. Thus, the selection of surfactants plays a key role in the formulation of SMEDDS. Extension of the solubility test, flask inversion process, and transmittance was also considered to screen the ability of surfactants and cosurfactants to emulsify. The findings are listed in Table 1. Tween 80 showed high transmittance (101.2\%) and lower flask inversions (2) with capryol 90 (oil) to form homogeneous emulsion compared with tween 20 to labrasol. L-SMEDDS was therefore formulated using capryol 90 (oil), tween 80 (surfactant), and labrasol (co-surfactant).

\subsection{Ternary phase diagram}

To describe the self-microemulsifying area and optimize the concentration of oil, surfactant, and cosurfactant in L-SMEDDS formulations, a ternary phase diagram was constructed. The phase diagram for the different ratios of surfactants and co-surfactants is shown in Figure 1. A rise in surfactant concentration increases the self-emulsifying area, but drug precipitation has been observed in 1:1. Increased surfactant concentration improves solubilization and thus shows an increased area of the microemulsion. 
Table 1. The solubility of DP in various vehicles and emulsification efficiency of surfactants and cosurfactants.

\begin{tabular}{|c|c|c|c|c|}
\hline Vehicles & $\begin{array}{l}\text { Solubility at } 2^{\circ} \mathrm{C} \\
(\mathrm{mg} / \mathrm{mL})^{*}\end{array}$ & Transmittance $(\%)$ & No. of flask inversion & Appearance $* * *$ \\
\hline \multicolumn{2}{|l|}{ Oils tested: } & \multicolumn{3}{|l|}{ Surfactant } \\
\hline Capryol 90 & $154.810 \pm 0.040$ & \multicolumn{3}{|l|}{ Tween 80} \\
\hline Isopropyl Myristate & $0.730 \pm 0.006$ & 101.2 & 2 & Transparent \\
\hline Oleic acid & $1.773 \pm 0.038$ & \multicolumn{3}{|l|}{ Labrasol } \\
\hline Ethyl oleate & $3.100 \pm 0.010$ & 63.5 & 3 & Transparent \\
\hline Olive oil & $0.402 \pm 0.004$ & \multicolumn{3}{|l|}{ Tween 20} \\
\hline Maisine & $3.090 \pm 0.010$ & \multirow[t]{5}{*}{99.3} & \multirow[t]{5}{*}{4} & \multirow[t]{5}{*}{ Transparent } \\
\hline Labrafac PG & $1.620 \pm 0.010$ & & & \\
\hline Lauroglycol 90 & $12.653 \pm 0.534$ & & & \\
\hline Lauroglycol FCC & $6.627 \pm 0.074$ & & & \\
\hline Labrafil M 1944 CS & 17.8570 .067 & & & \\
\hline \multicolumn{2}{|c|}{ Surfactant/co-surfactant tested: } & \multicolumn{3}{|l|}{ Co-surfactant } \\
\hline Labrasol & $424.483 \pm 5.016$ & \multicolumn{3}{|l|}{ Labrasol } \\
\hline Tween 80 & $189.827 \pm 2.541$ & 100.40 & \multirow[t]{2}{*}{2} & \multirow[t]{2}{*}{ Transparent } \\
\hline Tween 20 & $144.421 \pm 0.582$ & Transcutol P & & \\
\hline Span 80 & $4.900 \pm 0.053$ & 99.73 & 4 & Transparent \\
\hline Span 20 & $4.150 \pm 0.053$ & \multicolumn{3}{|l|}{ PEG 200} \\
\hline Cremophore EL & $0.065 \pm 0.001$ & 99.35 & 3 & Transparent \\
\hline PEG $400^{* *}$ & $79.683 \pm 0.125$ & \multicolumn{3}{|l|}{ PEG 400} \\
\hline \multirow[t]{3}{*}{ Transcutol } & $26.277 \pm 0.015$ & 98.36 & 4 & Transparent \\
\hline & & \multicolumn{3}{|l|}{ Kollisolve 400} \\
\hline & & 98.14 & 3 & Transparent \\
\hline
\end{tabular}

Co-surfactant is an important part of microemulsion, but its optimal concentration is very much needed. Figure 1 indicates a substantial decrease in the micro-emulsification area with an increased concentration of co-surfactants. Different concentrations of oil, surfactant, and co-surfactants were collected from the self-micro emulsifying area to prepare formulations (Table 2) and assessed for their stability.

\subsection{Evaluation and characterization of L-SMEDDS}

\subsubsection{Dispersity test and percent transmittance}

If percent transmittance is above $90 \%$, then formulations have a transparent nature [18]. The results of percent transmittance are shown in Table 3. All prepared formulations showed a transmittance value greater than $90 \%$, suggesting their clarity. Smaller particle size supported by droplet size analysis might be contributing to the transparency of the formulations.

\subsubsection{Heating cooling cycle and centrifugation testing}

Over three consecutive heating-cooling cycles, a total of nine formulations of DP loaded L-SMEDDS were subjected, and results are tabulated in Table 3. Biphasic systems undergoing centrifugation allow two phases to develop if the system is not physically stable. Formulations F1, F4, and F8 have been able to withstand the stress conditions that suggest long-term stability at the ambient conditions. The centrifugation results are shown in Table 3.

\subsubsection{Evaluation of DP loaded L-SMEDDS}

L-SMEDDS diluted at infinite dilutions, there is the risk of immediate surfactant and co-surfactant separation from an oily process accompanied by oily globule coalescence. This likelihood has been checked for the test of dilution by robustness. In Table 4, results are expressed as transmittance percentages. Our study results showed that selected formulations were immune to specific dilution media, as well as the dilution medium volume [19]. 

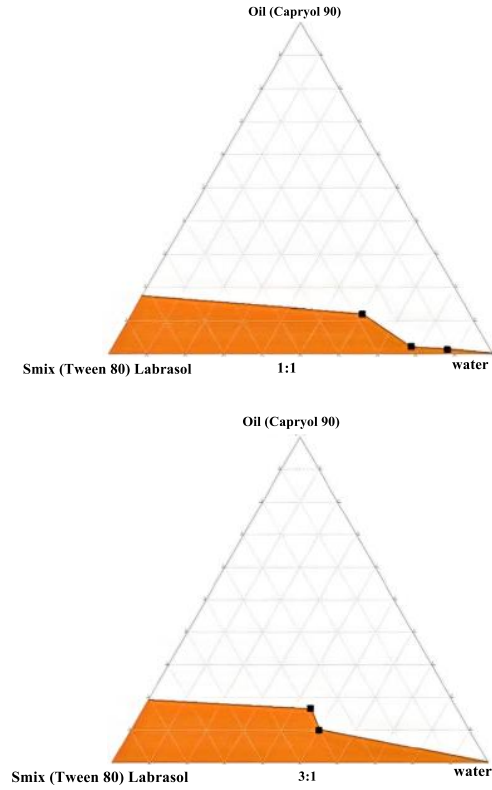
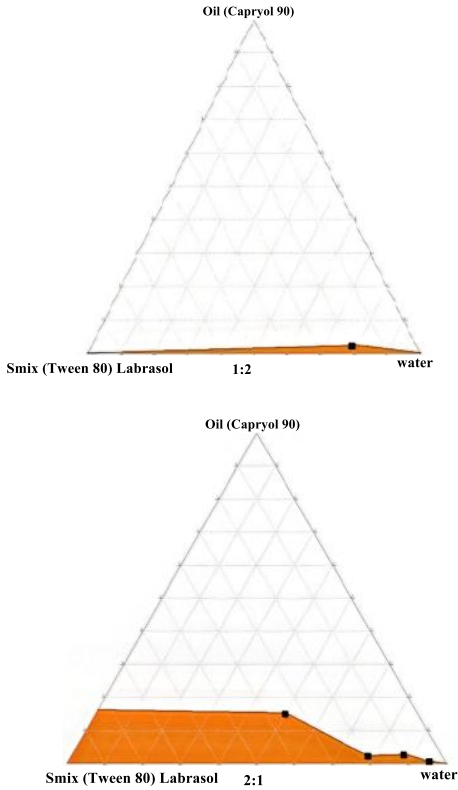

Figure 1. Ternary phase diagram of a system with the following components: Capryol 90 (Oil), Tween 80 (Surfactant), Labrasol (Co-surfactant) (Smix) a) 1:1, b)1:2, c)2:1 d)3:1.

Table 2. Composition of DP loaded L-SMEDDS.

\begin{tabular}{lccccccccc}
\hline Composition (\% w/w) & F1 & F2 & F3 & F4 & F5 & F6 & F7 & F8 & F9 \\
\hline Capryol 90 & 10 & 20 & 30 & 10 & 10 & 20 & 30 & 10 & 20 \\
S/Cos ${ }^{* *}$ ratio & $\mathbf{1 : 1}$ & $\mathbf{1 : 1}$ & $\mathbf{1 : 1}$ & $\mathbf{1 : 2}$ & $\mathbf{2 : 1}$ & $\mathbf{2 : 1}$ & $\mathbf{2 : 1}$ & $\mathbf{3 : 1}$ & $\mathbf{3 : 1}$ \\
Tween 80 & 45 & 40 & 35 & 30 & 60 & 53.3 & 46.6 & 67.5 & 60 \\
Labrasol & 45 & 40 & 35 & 60 & 30 & 26.7 & 23.4 & 22.5 & 20 \\
\hline * In all formulations the amount of DP was constant (25 mg) \\
**(S/Cos indicates surfactant/co-surfactant)
\end{tabular}

The rate and degree of drug release, as well as absorption, are depend on droplet size, hence droplet size is a crucial factor in SMEDDS efficiency. The results for droplet size distribution of optimized batches are reported in Table 4. The mean particle size was found to be 16.5, 96.7 and $10.3 \mathrm{~nm}$ respectively for F1 (1:1), F4 (1:2) and F8 (3:1). Presence of high concentration of surfactant (tween 80) to stabilize oil-water interface in F8 might be contributing the smaller particle size. This result was in consistent with previous finding reported in Wei et al., (2005) [20], Kommuru and Gurley, (2001) [21] and Levy and Benita, (1990) [22].

PDI of formulation F1 and F4 was 0.331 and 0.304 respectively. PDI closer to zero indicates uniformity in the size distribution. Excess concentration of surfactant in F8 (3:1) might be contributing in formation of micelles. Polydispersity exhibited by F8 (0.491) could be due to formed non interacting aggregates (micelles) and microemulsion upon dilution [23].

Zeta potential controls the degree of repulsion between adjacent or similarly charged and distributed droplets; it has the functional stabilizing effect. The zeta potential outcomes are shown in Table 4. The negative charge on SMEDDS resulted from esters and fatty acids in capryol 90, which was present in the formulation as an oil phase. Formulations F1, F4, and F8 contain more than $99 \%$ of the drug content. Drug content results are outlined in Table 4.

The analysis of drug precipitation was performed to check presence and absence of precipitation of the formulations after dilution [24, 25]. Formulations F1, F4, and F8 were diluted with distilled water and diluted solutions were observed for $1 \mathrm{~h}$ and $6 \mathrm{~h}$ for a sign of precipitation. No signs of $1 \mathrm{~h}$ and $6 \mathrm{~h}$ precipitation was demonstrated the stability of the prepared L-SEMDDS. The temperature at which formulation transforms into cloudy appearance was reported as the cloud point. L-SMEDDS sensitivity to higher temperatures can result in phase separation. Ideally, it should have a cloud point greater than $37^{\circ} \mathrm{C}$. All three formulations in the present study display a high cloud point greater than $70^{\circ} \mathrm{C}$ (Table 4 ). 
Table 3. Data for evaluation of L-SMEDDS

\begin{tabular}{cccccc}
\hline $\begin{array}{c}\text { Formulation } \\
\text { code }\end{array}$ & $\begin{array}{c}\text { Dispersibility } \\
\text { Time (sec) }\end{array}$ & $\begin{array}{c}\text { \% } \\
\text { Transmittance* }\end{array}$ & $\begin{array}{c}\text { Visual } \\
\text { grade }\end{array}$ & $\begin{array}{c}\text { Heating cooling } \\
\text { cycle** }\end{array}$ & $\begin{array}{c}\text { Centrifugation } \\
\text { (5000 rpm; 20 } \\
\text { minutes) }\end{array}$ \\
\hline F1 & 30 & 100.02 & A & Passed & Passed \\
F2 & 40 & 98.82 & B & Failed & Failed \\
F3 & 45 & 97.28 & B & Failed & Failed \\
F4 & 40 & 99.02 & B & Passed & Passed \\
F5 & 22 & 100.20 & A & Failed & Failed \\
F6 & 35 & 100.14 & B & Failed & Failed \\
F7 & 40 & 99.66 & B & Failed & Failed \\
F8 & 20 & 100.30 & A & Passed & Passed \\
F9 & 30 & 100.36 & A & Failed & Failed \\
\hline
\end{tabular}

*Results are expressed as mean \pm SD $(n=3)$

**Grade A displays clear appearance while grade B exhibits a buish whitish appearacne rapidely after dilution.

*** Results were based on the stability of the formulation after 3 consecutive cycles of heating-cooling cycles.

Table 4. Evaluation parameters for optimized batches.

\begin{tabular}{|c|c|c|c|c|c|c|c|c|c|c|}
\hline \multirow{2}{*}{$\begin{array}{l}\text { Formulation } \\
\text { code }\end{array}$} & \multicolumn{3}{|c|}{$\%$ Transmittance ${ }^{*}$} & \multirow{2}{*}{$\begin{array}{l}\text { Drug } \\
\text { content } \\
(0 \%)\end{array}$} & \multirow{2}{*}{$\begin{array}{l}\text { Particle } \\
\text { size } \\
\text { mean } \\
(\mathrm{nm})\end{array}$} & \multirow{2}{*}{$\begin{array}{c}\text { Zeta } \\
\text { potential } \\
(\mathrm{mV})\end{array}$} & \multirow{2}{*}{$\begin{array}{l}\text { Polydispersity } \\
\text { index } \\
\text { (PDI) }\end{array}$} & \multirow{2}{*}{$\begin{array}{c}\text { Cloud } \\
\text { point } \\
\left(\text { Temp. }{ }^{\circ} \mathrm{C}\right)\end{array}$} & \multicolumn{2}{|c|}{$\begin{array}{l}\text { Drug } \\
\text { precipitation } \\
\text { study }\end{array}$} \\
\hline & $\begin{array}{l}\text { Distilled } \\
\text { water }\end{array}$ & $\begin{array}{l}0.1 \mathrm{~N} \\
\mathrm{HCl} \\
(1.2 \\
\mathrm{pH})\end{array}$ & $\begin{array}{c}\text { Phosphate } \\
\text { Buffer } \\
(7.4 \mathrm{pH})\end{array}$ & & & & & & $\begin{array}{c}\text { After } \\
1 \text { hr }\end{array}$ & $\begin{array}{l}\text { After } \\
6 \mathrm{hr}\end{array}$ \\
\hline $\mathrm{F} 1$ & 96.57 & 96.15 & 94.25 & $\begin{array}{l}99.23 \\
\pm 0.11\end{array}$ & 16.5 & $\begin{array}{c}-9.6 \\
\pm 0.22\end{array}$ & 0.331 & 73 & $\begin{array}{l}91.51 \\
\pm 2.62\end{array}$ & $\begin{array}{l}93.63 \\
\pm 0.39\end{array}$ \\
\hline $\mathrm{F} 4$ & 95.36 & 93.64 & 96.45 & $\begin{array}{l}99.12 \\
\pm 0.33\end{array}$ & 96.7 & $\begin{array}{l}-25.01 \\
\pm 1.50\end{array}$ & 0.304 & 71 & $\begin{array}{l}93.22 \\
\pm 1.33\end{array}$ & $\begin{array}{c}95.9 \\
8 \pm 0.13\end{array}$ \\
\hline FS & 95.31 & 100.01 & 100.06 & $\begin{array}{l}99.60 \\
\pm 0.21\end{array}$ & 10.3 & $\begin{array}{l}-21.7 \\
\pm 0.92\end{array}$ & 0.491 & 72 & $\begin{array}{l}96.02 \\
\pm 2.20\end{array}$ & $\begin{array}{l}98.35 \\
\pm 0.13\end{array}$ \\
\hline
\end{tabular}

*Transmittance after 1:100 dilutions with the respective medium

\subsubsection{In vitro drug release studies}

Figure 2 show results for the in vitro release of DP in 120 minutes. Nearly $100 \%$ release of DP from all formulations suggests the solubility enhancing the potential of SMEDDS formulations as opposed to plain product $(20 \%)$. The presence of oil and surfactant in SMEDDS causes very small spontaneous droplet formation, which allows the maximum available surface area to get in touch with the dissolution medium and eventually promotes rapid release [26]. As predicted, F8 is showing faster release due to a higher surfactant concentration compared with F1 and F4. Our study findings also suggest the shift in the dissolution medium did not alter DP's release pattern. DP structure indicates the absence of an ionizable group, which may be the explanation for the DP's in-vitro release pattern not changing. The findings of the research on drug release in vitro demonstrate that an increase in surfactant greatly enhances the release of drugs. The maximum release of drugs has been found in F8 formulation, which contains the optimum amount of oil required for self-emulsification.

\subsubsection{Ex-vivo permeation study}

Figure 2 presents the findings of the analysis of ex-vivo permeation of DP loaded L-SMEDDS formulation via rat duodenum. After a 120-minute permeation test review, the amount of drug permeated from formulations containing capryol 90 was 10.36 percent compared to 1.63 percent of pure drug. Ex-vivo research also supports SMEDDS's capacity for solubility enhancement and subsequently resulted in faster permeation via rat duodenum.

\subsection{Evaluation of SOLID SMEDDS}

A three-level, three-factor Box-Behnken model has been used in the current study to proceed 15 runs, with 12 factorial points and 3 centre points repeated. Centre points have been used to reduce experimental error and this contributes to an improvement in design accuracy. 


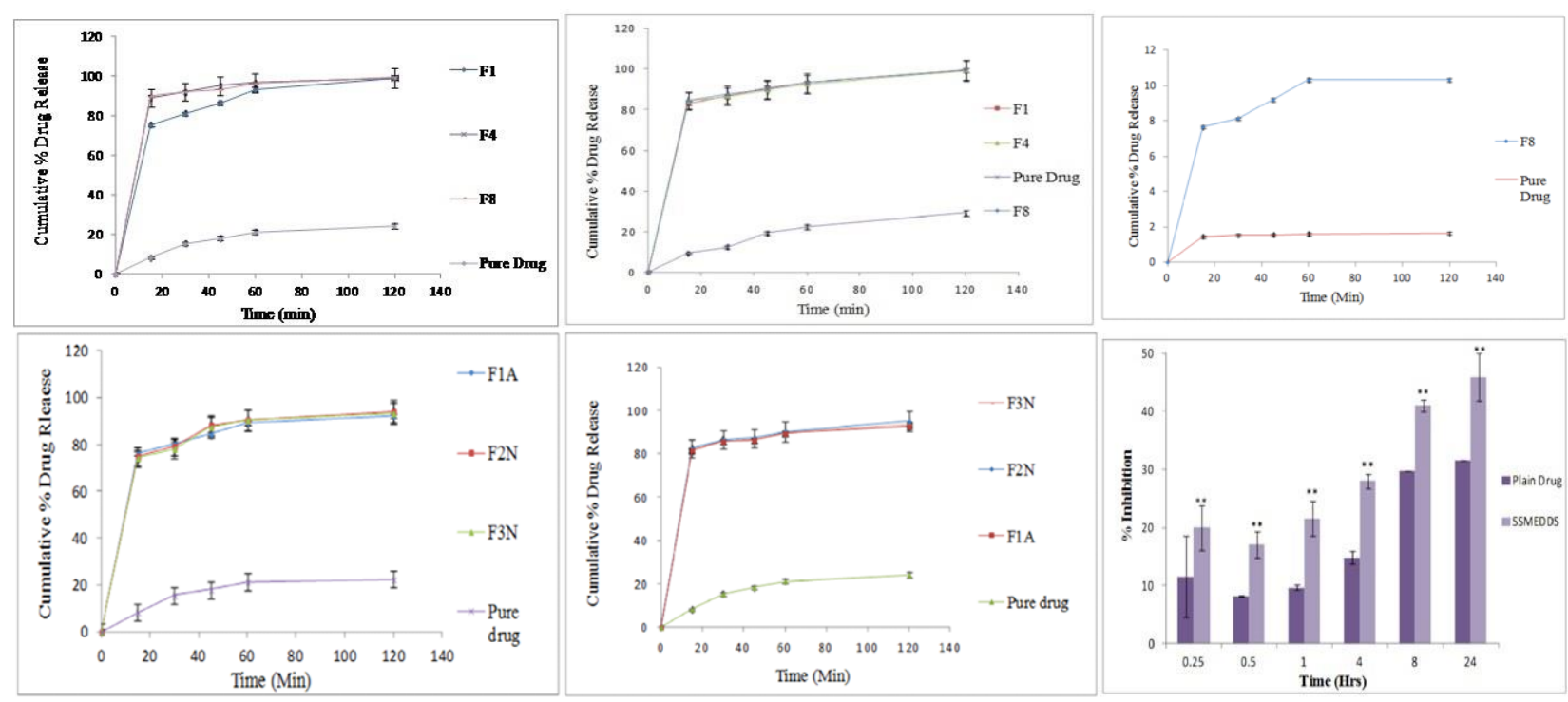

Figure 2. In vitro drug release study of pure drug and optimized batches of liquid SMEDDS and solid SMEDDS in gastric fluid $\mathrm{pH} 1.2$ and intestinal fluid $\mathrm{pH}$ 7.4. Effect of S-SMEDDS and plain DP on \% Inhibition of Paw edema. Results are expressed as average $\pm \operatorname{SEM}(n=6)$ (All data was subjected to ONE way ANOVA followed by Dunnett multiple comparisons test. All groups were compared with control. ${ }^{* *} \mathrm{p}<0.01$, plain DP showed non-significance).

To identify relevant independent factors and respective ranges, preliminary screening studies were performed. The temperature used does not caused thermal degradation of drying material. Hence the maximum inlet temperature level was selected at $150{ }^{\circ} \mathrm{C}$, below the DP melting point. The absence of condensation in the drying chamber allowed to select the feed flow rate of $8 \mathrm{ml} / \mathrm{min}$. Due to the higher viscosity of the feed solution, high carrier concentration will block the needle and also responsible for increased weight of S-SMEDDS equal to single-dose DP. The variables selected, their levels and experimental design, and the responses observed for the Box-Behnken design are summarized in Table 5.

As indicated by the Design - Expert ${ }^{\circledR}$ program, the sequential model number of squares, model summary statistics, lack of fit test, were performed for all the responses. All the responses were better suited to the quadratic model. Table 7 presents the final polynomial equations after the reduction of the model and a description of the regression analysis on all the responses. For Y1 and Y2 responses, the multiple correlation coefficients $\left(\mathrm{R}^{2}\right)$ are 0.9949 and 0.9924 respectively, suggesting a good fit. Also, ANOVA has clarified and confirmed the statistical validity of the model fit and justified by ANOVA in Table 6 .

Lack of fit test justifies that the variation of mean around the fitted model. If the lack of fit is significant, the model does not fit for the data well and is inadequate for the variation of responses in the system. Non-significance of lack of fit $(p>0.05)$ for all other calculated responses confirms model reliability. The p-value obtained from the ANOVA should be less than 0.05 for model variance, and that obtained from the lack of fit test should be greater than 0.05 . Table 6 displays P-values which are considered to be less than 0.05 and which suggest an acceptable pattern.

\subsection{Response surface analysis}

Graphs of a three-dimensional response surface were plotted based on model polynomial equations. Such types of graphs are also useful for analyzing the impact on the responses between two different variables at a time. The third element at the middle level was kept constant in all of the figures presented. For all responses, curvatures and non-linear relationships have been analyzed in the response surface graph which indicates the interaction between the independent variables (Figures 3 and 4).

The droplet size (Y1) is a crucial factor for evaluating SMEDDS. Due to the greater interfacial region, the formation of smaller droplet size causes an increase in drug absorption after dispersion. Like other spray drying factors, the concentration of the carrier can influence the droplet size significantly. Droplet size (Y1) of the emulsion after spray dried SMEDDS was reconstituted in distilled water ranged from 87.5 to $175 \mathrm{~nm}$. Figure 3 demonstrates the effects of A, B, C on the response (Y1) and its interactions. Figure 3 shows that the temperature of the inlet and the concentration of the carrier significantly impacted droplet size. A substantial 
reduction in droplet size at the reduced feed rate was observed at $130^{\circ} \mathrm{C}$ inlet temperature. This antagonistic action of inlet temperature and the feed flow rate was also explained in the quadratic equation for response Y1 by the positive and negative coefficients respectively. Interestingly, heightened droplet size was observed at the carrier concentration mid-value. Conclusively, the maximum inlet temperature and carrier concentration substantially decreased the droplet size.

Table 5. Variables and their levels used in Box -Behnken Design and experimental design and observed responses for the Box-Behnken design.

\begin{tabular}{cccccc}
\hline \multirow{2}{*}{ Independent variables } & \multicolumn{5}{c}{ Levels actual (coded) } \\
\cline { 2 - 6 } & Low (-1) & Middle (0) & High (+1) \\
\hline A: Inlet Temperature $\left({ }^{\circ} \mathrm{C}\right)$ & 130 & & 140 & 150 \\
B: Feed flow rate $(\mathrm{ml} / \mathrm{min})$ & 4 & 6 & & 8 \\
C: Carrier concentration (\%) & 0.25 & & 0.50 & $\mathbf{Y}_{\mathbf{1}}$ & $\mathbf{\mathbf { Y } _ { \mathbf { 2 } }}$ \\
\hline & & & $\mathbf{C}$ & Particle & practical \\
Run & $\mathbf{A}$ & $\mathbf{B}$ & & size (nm) & yield \% \\
\hline 1 & & & 0.5 & 130 & 37 \\
2 & 140 & 6 & 0.5 & 134 & 42 \\
3 & 150 & 8 & 0.5 & 125 & 36.96 \\
4 & 140 & 6 & 0.5 & 128 & 37 \\
5 & 140 & 6 & 0.25 & 150 & 40.01 \\
6 & 150 & 4 & 0.5 & 130 & 32.01 \\
7 & 130 & 4 & 0.25 & 140 & 32.04 \\
8 & 140 & 6 & 0.25 & 87.5 & 30.6 \\
9 & 130 & 4 & 0.5 & 175 & 40.56 \\
10 & 150 & 8 & 0.75 & 95 & 38.23 \\
11 & 140 & 4 & 0.75 & 132 & 36.53 \\
12 & 140 & 6 & 0.75 & 126 & 42.66 \\
13 & 150 & 6 & 0.75 & 95 & 38.94 \\
14 & 130 & 8 & 0.5 & 100 & 35.08 \\
15 & 130 & 8 & 0.25 & 105 & 32.35 \\
\hline
\end{tabular}

Table 6. ANOVA for Quadratic model.

\begin{tabular}{lcccccccc}
\hline \multirow{2}{*}{ Source } & \multicolumn{2}{c}{ Sum of squares } & \multicolumn{2}{c}{ Mean of squares } & \multicolumn{2}{c}{ F-values } & \multicolumn{2}{c}{ p-value } \\
\cline { 2 - 9 } & $\mathbf{Y}_{\mathbf{1}}$ & $\mathbf{Y}_{\mathbf{2}}$ & $\mathbf{Y}_{\mathbf{1}}$ & $\mathbf{Y}_{\mathbf{2}}$ & $\mathbf{Y}_{\mathbf{1}}$ & $\mathbf{Y}_{\mathbf{2}}$ & $\mathbf{Y}_{\mathbf{1}}$ & $\mathbf{Y}_{\mathbf{2}}$ \\
\hline Model & 7698.15 & 197.91 & 855.35 & 21.99 & 108.67 & 72.58 & $<0.0001$ & $<0.0001$ \\
A-inlet temp & 3719.53 & 102.24 & 3719.53 & 102.24 & 472.57 & 337.48 & $<0.0001$ & $<0.0001$ \\
B-feed flow rate & 2556.13 & 5.31 & 2556.13 & 5.31 & 324.76 & 17.54 & $<0.0001$ & 0.0086 \\
C-carrier conc & 148.78 & 57.03 & 148.78 & 57.03 & 18.90 & 188.24 & 0.0074 & $<0.0001$ \\
$\mathrm{AB}$ & 30.25 & 0.6642 & 30.25 & 0.6642 & 3.84 & 2.19 & 0.1072 & 0.1988 \\
$\mathrm{AC}$ & 248.06 & 8.09 & 248.06 & 8.09 & 31.52 & 26.72 & 0.0025 & 0.0036 \\
$\mathrm{BC}$ & 1.0000 & 0.4830 & 1.0000 & 0.4830 & 0.1271 & 1.59 & 0.7361 & 0.2624 \\
$\mathrm{~A}^{2}$ & 12.69 & 12.57 & 12.69 & 12.57 & 1.61 & 41.50 & 0.2600 & 0.0013 \\
$\mathrm{~B}^{2}$ & 100.96 & 7.44 & 100.96 & 7.44 & 12.83 & 24.56 & 0.0158 & 0.0043 \\
$\mathrm{C}^{2}$ & 819.27 & 2.24 & 819.27 & 2.24 & 104.09 & 7.41 & 0.0002 & 0.0417 \\
\hline
\end{tabular}

The practical yield (Y2) from L-SMEDDS spray drying with aerosil- 200 as a carrier ranged from $30.6 \%$ to $42.66 \%$. Limitation in the yield (nearly $50-70 \%$ ) is due to difficulty in collecting all fine particles with a lower mass in laboratory spray drying operations. Most low mass particles are quickly consumed by the aspirator and are not deposited effectively in the cyclone, resulting in low yield. Figure 4 shows that, regardless of flow rate, yield increased significantly as the temperature at the inlet increased. Nevertheless, there was a low yield at lower carrier concentration and lower inlet temperature, when carrier concentration was taken into account. Then yield increased significantly at higher carrier concentration and high inlet temperature. It may mean that higher inlet temperatures contributed to significant drying of liquid feed resulting in reduced sticking in the drying chamber and cyclone wall and eventually resulting in increased yield. Our findings indicated that increasing inlet temperature and carrier concentration could increase yield. 

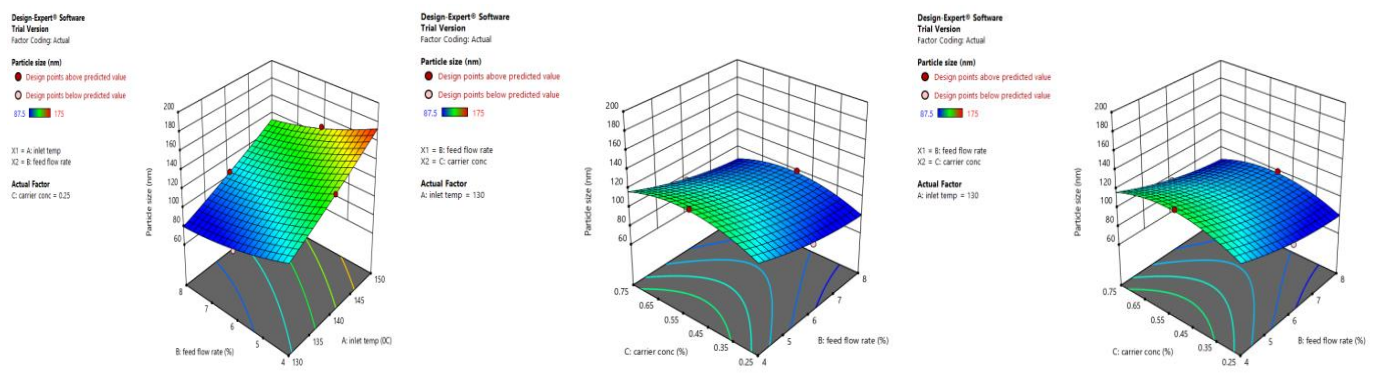

Figure 3. The response surface plots showing the effect of inlet temperature (A), feed rate (B) and carrier concentration $(\mathrm{C})$ on particle size $\left(\mathrm{Y}_{1}\right)$.
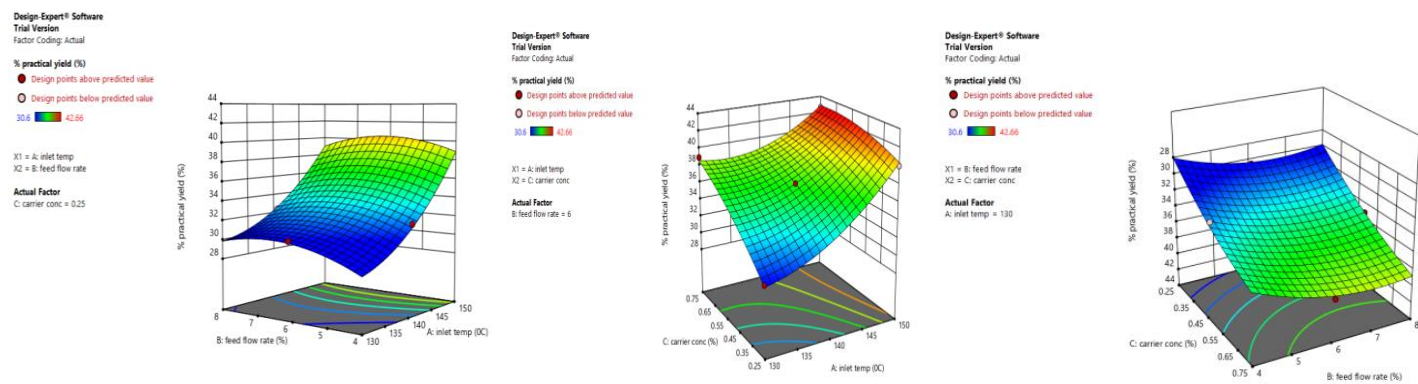

Figure 4. The response surface plots showing the effect of inlet temperature (A), feed rate (B) and carrier concentration $(\mathrm{C})$ on practical yield $\left(\mathrm{Y}_{2}\right)$.

\subsection{Optimization}

All the calculated responses were simultaneously optimized graphically using the desirability function by giving equal importance to all of the responses. Figure 5 displays the plots of all factors showing the effect on particle size (Y1) and practical yield (Y2) of the inlet temperature (A), feed rate (B) and carrier concentration (C). Optimum parameters were selected in the final formulation based on criteria for minimizing particle size (Y1) and optimizing percent yield (Y2). After a large grid quest over the domain, the global desirability feature suggested and defined the best-suited compromise region. The optimized inlet temperature (A), feed rate (B) and carrier concentration (C) parameter values were $130{ }^{\circ} \mathrm{C}, 6 \mathrm{~mL} / \mathrm{min}$, and $0.25 \%$ respectively. Five batches of S-SMEDDS were prepared according to optimum parameters to confirm the validity of the optimization capabilities of the established model, as well as the reproducibility of this system. The experimental values particle size (Y1) and practical yield (Y2) were $87.5 \pm 4.95 \mathrm{~nm}$ and $34.06 \pm$ $1.70 \%$ respectively (Table 7 ). Results obtained from optimum spray dryer parameter settings were closely related to those the model predicts. Therefore, these findings showed good predictability behavior from the established spray drying theoretical model and also proved to be correct in efficacy in both repeatability and reproducibility in the optimization process. Various types of the contour plot give different interactions between variables. An elliptical contour plot gives interaction between variables while the circular contour plot implies otherwise. Figure 6 and Figure 7 display elliptical plots of contour which indicate the interaction between variables.

\subsection{Flow properties of S-SMEDDS}

Flow properties play an important role in the S-SMEDDS capsular filling cycle. It should have good flow properties for acceptably dispensing S-SMEDDS in suitable dosage form. S-SMEDDS is tested for flow properties for all three batches and summarized in Table 8. Compared to F2N and F3N, F1A showed comparatively good flowability, spray drying of F1A could impart good flow properties. The results are given as mean $\pm S D(n=3)$.

\subsection{Drug content}

The drug content percentage results are illustrated in Table 8. More than 99 percent of the product content was observed for all S-SMEDDS formulations. 
Table 7. Summary of the regression analysis for responses $Y_{1}$ and $Y_{2}$ for fitting into a quadratic model and Validation of model optimization.

\begin{tabular}{|c|c|c|c|}
\hline Response & Polynomial equation & $\mathbf{R}^{2}$ & Adjusted $\mathrm{R}^{2}$ \\
\hline $\mathrm{Y}_{1}$ & $\begin{array}{c}+127.67+21.56^{*} \mathrm{~A}-17.88^{*} \mathrm{~B}-4.31^{*} \mathrm{C}-2.75^{*} \mathrm{AB}-7.88^{*} \mathrm{AC}- \\
0.5000^{*} \mathrm{BC}+1.85^{*} \mathrm{~A}^{2}\end{array}$ & 0.9949 & 0.9411 \\
\hline $\mathrm{Y}_{2}$ & $\begin{array}{c}+36.99+3.57^{*} \mathrm{~A}+0.8150^{*} \mathrm{~B}+2.67^{*} \mathrm{C}-0.4075^{*} \mathrm{AB}- \\
1.42^{*} \mathrm{AC}+0.3475^{*} \mathrm{BC}+1.85^{*} \mathrm{~A}^{2}-1.42^{*} \mathrm{~B}^{2}-0.7796^{*} \mathrm{C}^{2}\end{array}$ & 0.9924 & 0.9787 \\
\hline Responses & $\begin{array}{l}\text { Predicted value } \\
\end{array}$ & Observed value & Biasness* \\
\hline Particle size & 89.500 & $87.5 \pm 4.95$ & 2.23 \\
\hline $\begin{array}{l}\text { Practical } \\
\text { yield (\%) }\end{array}$ & 30.385 & $34.06 \pm 1.70$ & -12.09 \\
\hline
\end{tabular}

\subsection{Drug release study for SSMEDDS}

DP's optimized batch F8 loaded L-SMEDDS of oil to Smix ratio 1:9(3:1) was converted to S-SMEDDS with F1A, F2N, and F3N batch formulation code respectively. A study on drug release gives an idea about the developed system's self-emulsification capacity. This research was conducted to ensure the rapid release of medication into the dissolution medium. Drug release profiles containing DP loaded F1A, F2N, and F3N SMEDDS were assessed in gastric fluid $(\mathrm{pH}$ 1.2) and intestinal fluid $(\mathrm{pH}$ 7.4) and compared to the plain drug. Figure 2 displays the progress. Within 15 minutes, the simple product showed a 10 percent release. It was observed that all optimized S-SMEDDS batches in gastric fluid and intestinal fluid showed more than 70 percent and 80 percent release of drugs within 15 minutes, respectively. All formulations dispersed almost instantly, indicating high self-emulsification efficiency of the formulations that were produced. It can, therefore, be assumed that the conversion of L-SMEDDS into S- SMEDDS had retained the formulation's solubilizing capability.

\subsection{Reconstitution properties of S-SMEDDS}

\subsubsection{Dilution study}

The S-SMEDDS of all engineered formulations showed the formation of spontaneous micro emulsification with the absence of microemulsion phase separation or phase inversion after $2 \mathrm{~h}$ storage. The percent transmission for all reconstituted S-SMEDDS lots was over 99\%. Table 8 displays particle size and polydispersity index.

\subsection{Solid-state characterization of S-SMEDDS}

\subsubsection{Differential scanning calorimetry (DSC)}

Figure 8 displays the DSC thermograms of both DP and S-SMEDDS. The pure DP showed a very pointed endothermic peak at $180^{\circ} \mathrm{C}$ with a peak at $178.49^{\circ} \mathrm{C}$, corresponding to its melting point. The crystallinity of DP is confirmed by its sharp endothermal peak in Figure 8. DSC of S-SMEDDS formulated with aerosil 200 and Neusilin US2 showed no obvious endothermic peak that ensures that the presence of drugs dissolved at the molecular level in the formulation of S-SMEDDS is present in an amorphous form in the formulation. Since the amorphous state is considered a highly disordered state, the solid particles present in S-SMEDDS remain in a highly dissolved state, further confirming SMEDDS' ability to retain the substance in the dissolved state and thus enhancing the dissolution of the substance.

\subsubsection{X-Ray Diffraction (XRD) technique}

Crystallinity is seen from X-ray diffraction, and PXRD shows molecular structures within the crystals. In Figure 8, the physical state of DP in S-SMEDDS is checked by PXRD. The PXRD pattern (Figure 8) showed the presence of a large number of crystalline peaks in pure crystalline form that represent the existence of DP. No characteristic sharp crystalline peaks were found in S-SMEDDS PXRD, which indicated that the drug remained in the dissolved molecular state of S-SMEDDS, and was suddenly transformed from crystalline to amorphous form. Crystalline to amorphous transition may be responsible for the faster rate of dissolution of S-SMEDDS as amorphous materials with high internal energy dissolve at a much faster rate than crystalline forms. 

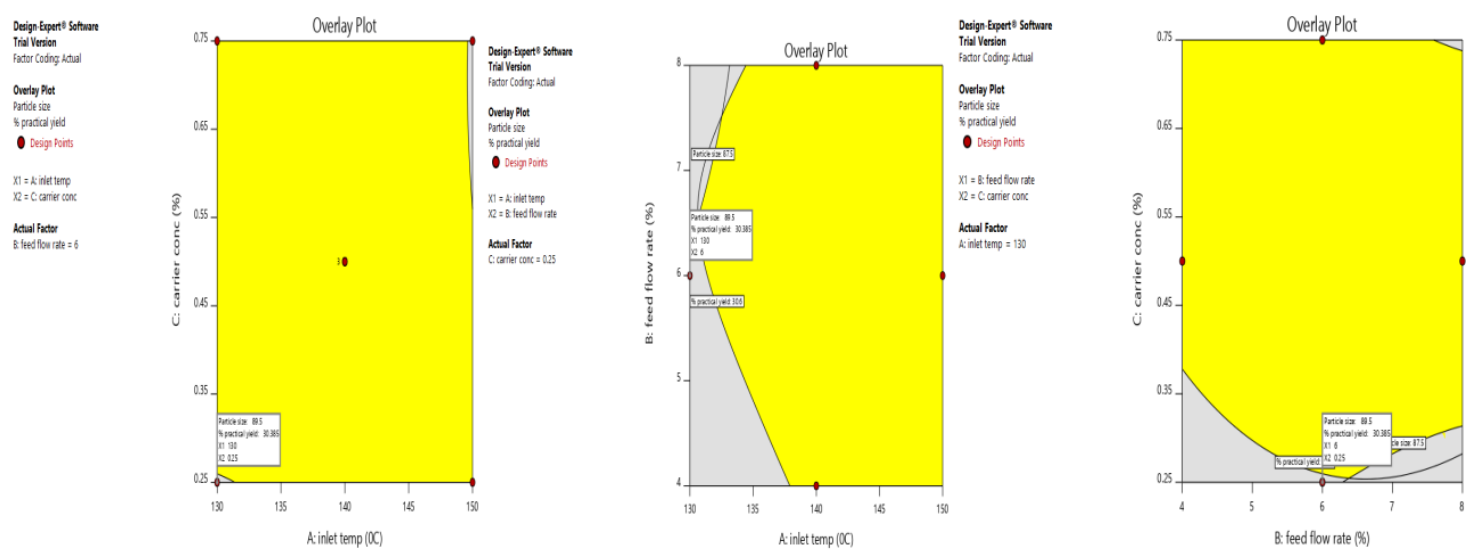

Figure 5. Overlay plots of all factors showing the effect of inlet temperature (A), feed rate (B) and carrier concentration $(\mathrm{C})$ on particle size $\left(\mathrm{Y}_{1}\right)$ and practical yield $\left(\mathrm{Y}_{2}\right)$.
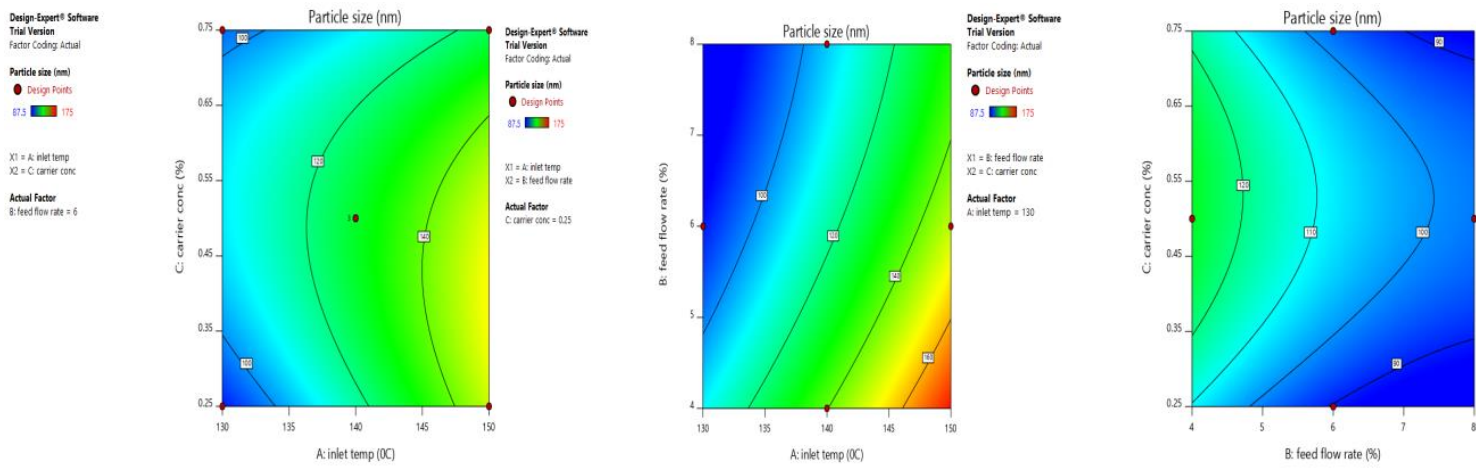

Figure 6. The contour plots showing the effect of inlet temperature (A), feed rate (B) and carrier concentration $(\mathrm{C})$ on particle size $\left(\mathrm{Y}_{1}\right)$.
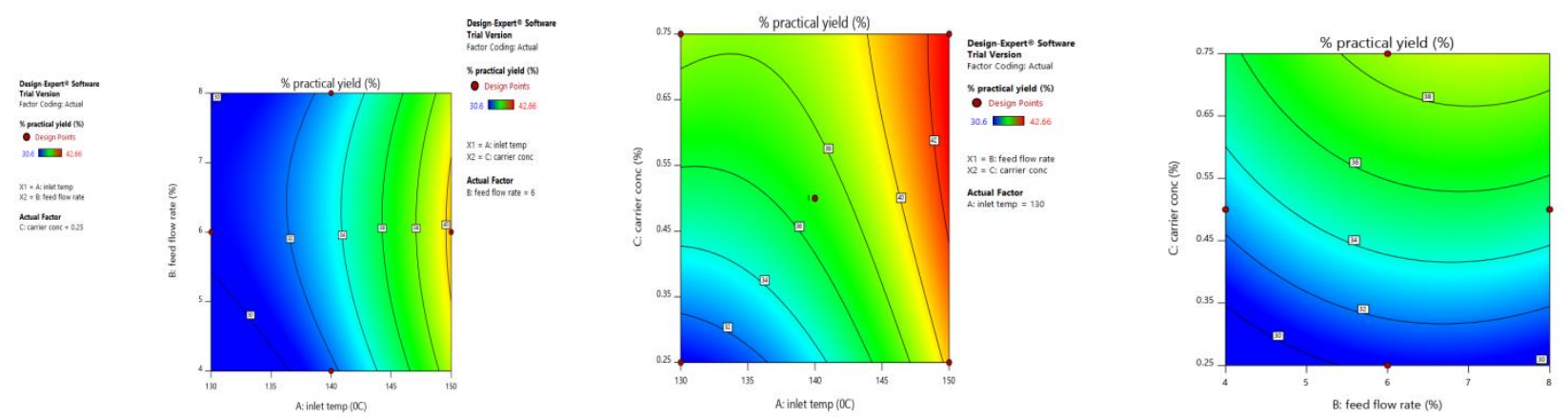

Figure 7. The contour plots showing the effect of inlet temperature (A), feed rate (B) and carrier concentration $(\mathrm{C})$ on percent practical yield $\left(\mathrm{Y}_{2}\right)$.

\subsubsection{Scanning Electron Microscopy (SEM)}

SEM (Figure 8) reflects the morphological characteristics of the DP, Neusilin US2 (F2N) S-SMEDDS, and Aerosil 200 (F1A). DP appeared as smooth, irregular, rectangular flakes of crystalline powders (Figure 8 A). Whereas S-SMEDDS prepared with carriers Neusilin US2 (Figure 8 B) and Aerosil 200 (Figure 8 C) showed rough-surfaced granular particles without any distinct crystallinity proof. S-SMEDDS of aerosil (Figure $8 \mathrm{C}$ ) shows free spherical particles which indicate that the L-SMEDDS are absorbed or can be coated in pores or aerosil surfaces.

\subsection{Anti-inflammatory activity of SMEDDS}

Anti-inflammatory activity was studied by comparison of the formulations of plain DP and SSMEDDS. The findings have been analyzed statistically. It is clear that after carrageenan injection there was a steady rise in the volume of the paw and it reached a limit at $24 \mathrm{~h}$. DP formulation S-SMEDDS $(12 \mathrm{mg} / \mathrm{kg})$ significantly prevented the production of edema after $30 \mathrm{~min}$. S-SMEDDS reported a reduction of 48.98 
percent in paw edema at $24 \mathrm{~h}(31.63$ percent) as opposed to plain DP. Important reduction $(\mathrm{p}<0.01)$ of paw edema in the community treated by S-SMEDDS relative to plain DP.

Carrageen-induced inflammation is used to test the anti-inflammatory activity of the drugs that suppress prostaglandin release, the non-steroidal anti-inflammatory drugs that specifically inhibit prostaglandin development.

\subsection{Stability studies}

Stability tests were conducted over a span of one month on L-SMEDDS (F8) and S-SMEDDS (F1A, $\mathrm{F} 2 \mathrm{~N}$, and F3N). The formulations were stored for one month in hard gelatin capsules at $40 \pm 2{ }^{\circ} \mathrm{C} / 75 \pm 5$ percent RH (climatic zone IV condition for accelerated stability testing as per ICH guidelines) to access their stability. Samples were extracted and tested for physical appearance, drug content percent, and studies of drug release as shown in Table 9. The results suggested the formulations could maintain their stability for up to a month.

\section{CONCLUSION}

This analysis successfully developed L-SMEDDS and S- SMEDDS for antileprotic DP. Optimized LSMEDDS with Capryol (10 percent w/w), Tween $80(67.5 / 5 \mathrm{w} / \mathrm{w})$, Labrasol $(22.5$ percent $\mathrm{w} / \mathrm{w})$ has been produced successfully with an increased dissolution rate compared to plain DP. L-SMEDDS has been successfully transformed into S-SMEDDS using Aerosil 200 and Neusiline US2 without changing the LSMEDDS properties. Solid-state characterizations as XRD and DSC indicated the existence of DP in SSMEDDS in a dissolved environment. The anti-inflammatory Wistar rat model shows a higher potential for S-SMEDDS pharmacodynamics as opposed to simple DP. The results of the stability studies indicated onemonth stability of the liquid and solid SMEDDS formulation. This study thus verified that DP's self-microemulsifying formulation can be established successfully as a potential alternative to a traditional oral formulation.

\section{MATERIALS AND METHODS:}

\subsection{Materials}

GlaxoSmithKline Pharmaceuticals Limited, Mumbai gave DP a kind gift. Gattefosse (Mumbai, India) gifted the following materials, which were used as received: Capryol 90, Maisine, Labrafac PG, Lauroglycol 90, Lauroglycol FCC, Labrafil M 1944 CS, and Labrasol. BASF Pvt had gifted Cremophore EL, Kollisolve PEG 200. (Mumbai, India) LTD. Neusilin from Gangwal Chemicals Pvt-Ltd., India was generously gifted. Tween 80 was purchased from Loba Chemie Pvt-Ltd., India. Aerosil 200 was purchased from Himedia Laboratories, Mumbai, India.
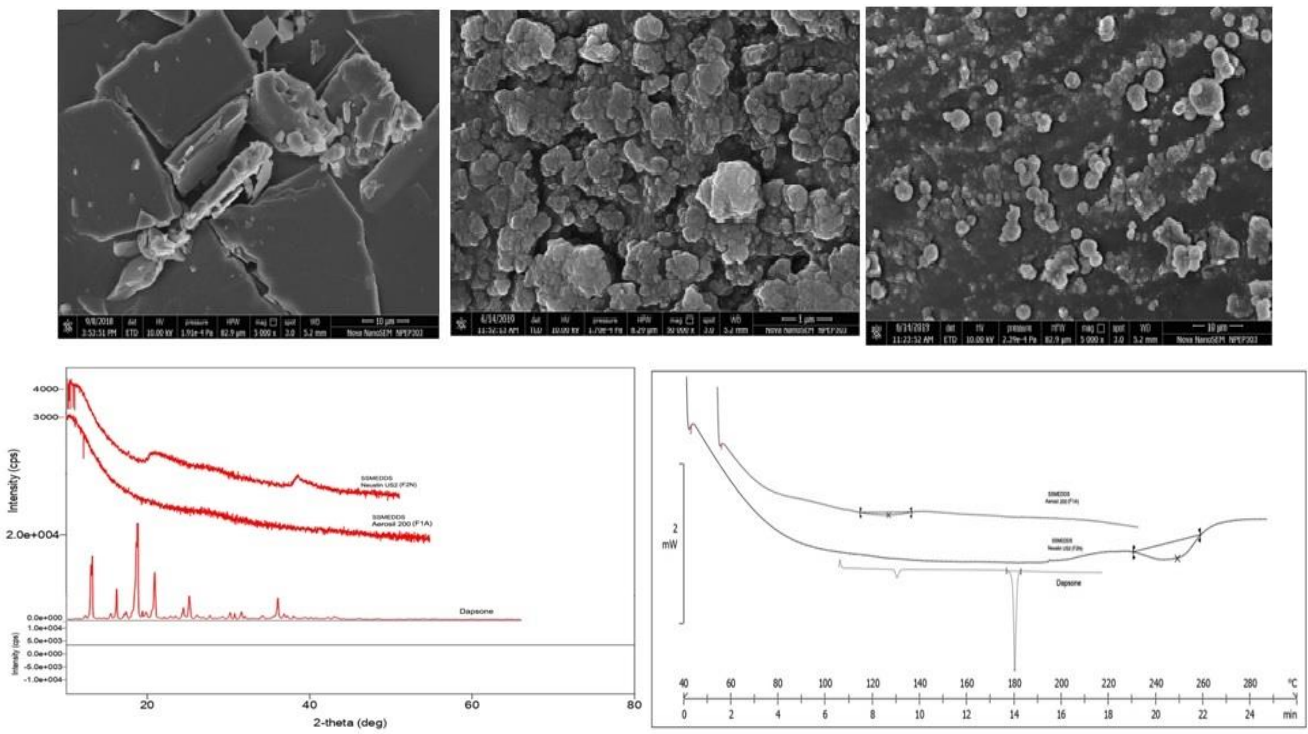

Figure 8. Morphological study of Plain DP and optimized batches of solid SMEDDS. 
Table 8. Data for flow properties, drug content and reconstituted study of all solid SMEDDS batches.

\begin{tabular}{|c|c|c|c|c|c|c|c|}
\hline $\begin{array}{l}\text { Formulation } \\
\text { code }\end{array}$ & $\begin{array}{c}\text { Oil : (S: Cos) } \\
\text { ratio }\end{array}$ & $\begin{array}{l}\text { Liquid } \\
\text { SMEDDS: } \\
\text { Carrier } \\
\text { ratio }\end{array}$ & $\begin{array}{l}\text { The angle of } \\
\text { repose }\left({ }^{\circ}\right)^{*}\end{array}$ & $\begin{array}{c}\text { Bulk Density } \\
(\mathrm{g} / \mathrm{mL})^{*}\end{array}$ & $\begin{array}{c}\text { Tapped density } \\
(\mathrm{g} / \mathrm{mL})^{*}\end{array}$ & $\begin{array}{l}\text { Hausners } \\
\text { ratio* }\end{array}$ & $\begin{array}{c}\text { Carrs index } \\
\%\end{array}$ \\
\hline F1A & $1: 9(3: 1)$ & $(1: 0.25)$ & $37.76 \pm 0.01$ & $0.28 \pm 0.002$ & $0.324 \pm 0.001$ & $1.126 \pm 0.001$ & $11.22 \pm 0.121$ \\
\hline $\mathrm{F} 2 \mathrm{~N}$ & 1:9(3:1) & $(1: 0.50)$ & $29.43 \pm 0.15$ & $0.363 \pm 0.003$ & $0.479 \pm 0.025$ & $1.75 \pm 0.007$ & $26.55 \pm 2.47$ \\
\hline F3N & 1:9(3:1) & $(1: 0.75)$ & $30.49 \pm 0.21$ & $0.376 \pm 0.002$ & $0.467 \pm 0.002$ & $1.238 \pm 0.005$ & $19.42 \pm 0.11$ \\
\hline Batch & $\begin{array}{c}\text { Oil : (S: Cos) } \\
\text { Ratio } \\
\text { L-SMEDDS } \\
\text { batch F8 }\end{array}$ & $\begin{array}{l}\text { Liquid } \\
\text { SMEDDS: } \\
\text { Carrier } \\
\text { ratio }\end{array}$ & $\begin{array}{c}\text { Drug } \\
\text { content }^{*}\end{array}$ & $\begin{array}{c}\text { Dilution } \\
\text { study } \\
\text { (appearance) }\end{array}$ & $\begin{array}{l}\text { Particle size* } \\
\text { (nm) }\end{array}$ & PDI* & $\begin{array}{c}\text { Percent } \\
\text { Transmittance* }\end{array}$ \\
\hline F1A & $1: 9(3: 1)$ & $(1: 0.25)$ & $99.43 \pm 0.037$ & Clear & $87.5 \pm 4.95$ & $0.491 \pm 0.022$ & $99.20 \pm 0.125$ \\
\hline F2N & $1: 9(3: 1)$ & $(1: 0.50)$ & $99.56 \pm 0.060$ & Clear & $241.8 \pm 3.72$ & $0.204 \pm 0.082$ & $99.43 \pm 0.479$ \\
\hline F3N & 1:9(3:1) & $(1: 0.75)$ & $99.43 \pm 0.03$ & Clear & $289.4 \pm 19.11$ & $0.321 \pm 0.025$ & $99.23 \pm 0.106$ \\
\hline
\end{tabular}

*Results are expressed as mean \pm SD $(n=3)$

Table 9. Data for stability study of the optimized formulation.

\begin{tabular}{|c|c|c|c|c|c|}
\hline \multirow[b]{2}{*}{ Days } & \multirow[b]{2}{*}{ Evaluations } & \multicolumn{4}{|c|}{ Formulations } \\
\hline & & $\begin{array}{l}\text { Liquid SMEDDS } \\
\text { (F8) }\end{array}$ & $\begin{array}{l}\text { Solid SMEDDS } \\
\text { (F1A) }\end{array}$ & $\begin{array}{l}\text { Solid SMEDDS } \\
\text { (F2N) }\end{array}$ & $\begin{array}{l}\text { Solid SMEDDS } \\
\text { (F3N) }\end{array}$ \\
\hline \multirow{3}{*}{0} & Appearance & Clear & $\begin{array}{l}\text { No colour } \\
\text { changes found }\end{array}$ & $\begin{array}{l}\text { No colour } \\
\text { changes found }\end{array}$ & $\begin{array}{l}\text { No colour } \\
\text { changes found }\end{array}$ \\
\hline & Percent of drug content* & $99.89 \pm 0.06$ & $99.79 \pm 0.06$ & $99.92 \pm 0.36$ & $99.69 \pm 0.06$ \\
\hline & $\begin{array}{l}\text { Percent of drug release*. } \\
\text { After } 120\end{array}$ & $99.50 \pm 0.90$ & $92.15 \pm 0.04$ & $95.30 \pm 0.19$ & $93.84 \pm 0.014$ \\
\hline \multirow{3}{*}{15} & Appearance & Clear & $\begin{array}{l}\text { No colour } \\
\text { changes found }\end{array}$ & $\begin{array}{l}\text { No colour } \\
\text { changes found }\end{array}$ & $\begin{array}{l}\text { No colour } \\
\text { changes found }\end{array}$ \\
\hline & Percent of drug content* & $99.41 \pm 0.02$ & $99.56 \pm 0.041$ & $99.46 \pm 0.12$ & $99.46 \pm 0.041$ \\
\hline & $\begin{array}{l}\text { Percent of drug release*. } \\
\text { After } 120\end{array}$ & $99.21 \pm 0.01$ & $91.99 \pm 0.032$ & $95.23 \pm 0.11$ & $93.49 \pm 0.012$ \\
\hline \multirow{3}{*}{30} & Appearance & Clear & $\begin{array}{l}\text { No colour } \\
\text { changes found }\end{array}$ & $\begin{array}{l}\text { No colour } \\
\text { changes found }\end{array}$ & $\begin{array}{l}\text { No colour } \\
\text { changes found }\end{array}$ \\
\hline & Percent of drug content* & $99.02 \pm 0.023$ & $99.01 \pm 0.036$ & $99.12 \pm 0.013$ & $99.06 \pm 0.036$ \\
\hline & $\begin{array}{l}\text { Percent of drug release*. } \\
\text { After } 120\end{array}$ & $99.03 \pm 0.03$ & $91.65 \pm 0.015$ & $95.06 \pm 0.23$ & $93.15 \pm 0.035$ \\
\hline
\end{tabular}

*Results are expressed as mean \pm SD $(n=3)$

\subsection{Animals}

In the carrageenan-induced anti-inflammatory tests, male wistar rats (Weighing between 150-180 g) were used. The animals were housed in standard polypropylene cages and maintained at room temperature $\left(24 \pm 2{ }^{\circ} \mathrm{C}\right)$; relative humidity $(60-70 \%)$ was maintained at $12 \mathrm{~h}$ light-dark period. The experimental procedure was approved by the Committee for Institutional Animal Ethics (IAEC), and all experiments were performed in compliance with the committee's guidelines for animal experiment supervision, India.

\subsection{Saturation Solubility of DP}

The saturation solubility of DP was assessed using the shaking process. The excess drug was added in a $5 \mathrm{ml}$ vial that contains $2 \mathrm{ml}$ of distilled water and methanol. To reach equilibrium, the vials were held in an orbital shaker at $37 \pm 2{ }^{\circ} \mathrm{C}$ for $48 \mathrm{~h}$. After achieving equilibrium, each vial was centrifuged for 5 minutes at $3000 \mathrm{rpm}$ and the supernatant was filtered using whatman filter paper, the filtrate was correctly mixed and diluted, and UV-spectrophotometer (1800, Shimadzu, Japan) was used to report absorbance at $290 \mathrm{~nm}$ [27].

\subsection{The solubility of DP in different vehicles}

The solubility of DP has been calculated in different oils, surfactants, and cosurfactants. In $2 \mathrm{ml}$ of each of the selected oils, surfactants and co-surfactants were taken separately in $5 \mathrm{ml}$ stoppered vials and combined by vortexing for 10-15 minutes, an excess of the drug was added in it. Furthermore, to maintain equilibrium, the vials were held at $37 \pm 2{ }^{\circ} \mathrm{C}$ in an isothermal water bath shaker for $48 \mathrm{~h}$. The equilibrated samples underwent centrifugation for 15-20 minutes at $3000 \mathrm{rpm}$. To extract insoluble DP, the obtained supernatants were filtered through whatman filter paper. The filtrate was mixed and diluted immediately. 
The concentration of the DP was quantified by UV- spectrophotometer (1800, Shimadzu, Japan) at $290 \mathrm{~nm}$ [28].

\subsection{Screening of surfactants and co-surfactants}

Surfactant selection depends on the efficiency of surfactant emulsification, which will indicate a higher percentage of transmittance. The emulsification potential of various surfactants and cosurfactants for selected oils was screened by flask inversion method. Briefly, equal proportion of selected oil and surfactants (300 mg each) was mixed, the mixture was heated gently to $40^{\circ} \mathrm{C}$ for $1-2$ minutes and allowed for uniform, vigorous homogenization. This mixture was added into double distilled water to observe, the number of flask inversions needed to form a homogenous emulsion. The emulsion was permitted to withstand for $2 \mathrm{~h}$ and a UV-1800 spectrophotometer (Shimadzu, Japan) measured its transmittance percentage at $638.2 \mathrm{~nm}$. A similar procedure described above was repeated for the selection of cosurfactant [29].

\subsection{Construction of ternary phase diagram}

The selection of oil, surfactant, and co-surfactant was made based on studies of solubility and flask inversion method. Capryol 90, tween 80, and labrasol respectively were picked as oil, surfactant, and cosurfactant. A ternary phase diagram was developed using a gradient method [19]. Gradient system facilitates the assessment of formulation upon dilution. Grade A displays clear appearance while grade B exhibits a bluish whitish appearance rapidly after dilution. Those formulations exhibit milky emulsion after 2 min termed as grade $\mathrm{C}$. While grade D an grade $\mathrm{E}$ require more than 2 mins form emulsifycation and exhibits dull grayish white emulsion. Briefly, a series of self-micro emulsifying systems with a varying weight percentage of capryol 90, tween 80, and labrasol was prepared. Since inserting the drug into the SMEDDS may have some effect on the boundary of self-emulsification, each system in the series consisted of $25 \mathrm{mg}$ of DP. SMEDDS $(0.2 \mathrm{ml})$ formulation was added to water $(200 \mathrm{ml})$ in a glass beaker held at $37^{\circ} \mathrm{C}$ and blended together. Spontaneous emulsifying ability and progress of spreading emulsion droplets were observed. When droplets dispersed easily in water and developed a fine milky or slightly bluish emulsion within $1 \mathrm{~min}$, the propensity to form an emulsion was assessed as 'strong.' When there was soft, slow, or no emulsion formation or when oil droplets coalesced when stirring was stopped or when dull, grayish-white emulsion was produced, it was considered bad. All studies have been replicated thrice. For further study [30], the extreme and middle level of the independent variables consisting of oil, surfactant, and cosurfactant were selected.

\subsection{Formulation of Liquid SMEDDS (L-SMEDDS)}

A series of nine batches of SMEDDS formulations were prepared by dissolving the necessary quantity of DP in oil then adding Smix to it. This mixture was gently stirred on a magnetic stirrer and heated in a water bath at $40^{\circ} \mathrm{C}$ until a clear preparation was obtained. The formulated mixture was packed in screwcapped glass tubes for further use at room temperature.

\subsection{Characterization of L-SMEDDS}

\subsubsection{Dispersibility test and percent transmittance}

Standard USP dissolution apparatus II (Veego Science, VDA-8D4) was used to investigate the efficiency of self-emulsification. Each formulation $(1 \mathrm{ml})$ was added at $37 \pm 0.5^{\circ} \mathrm{C}$ to $500 \mathrm{ml}$ of water [31]. Moderate stirring was imparted by a standard stainless steel dissolution paddle running at $50 \mathrm{rpm}$. From such dispersion, the in vitro accomplishment of the formulation is examined visually using an effective gradient method [32].

The formulation was introduced by using a magnetic stirrer (Eltek, MS205) in $100 \mathrm{ml}$ distilled water at $37 \pm 0.5^{\circ} \mathrm{C}$ with continuous stirring. UV-1800 Spectrophotometer (Shimadzu, Japan) was used to measure the percent transmittance at $650 \mathrm{~nm}$ [33].

\subsubsection{Heating and cooling cycle}

The heating and cooling process tested the stability of formulations. The formulations were subjected to a 3-4 freeze-thaw cycle, which included 24 hours freezing at $4{ }^{\circ} \mathrm{C}$ followed by 24 -hour thawing at $40{ }^{\circ} \mathrm{C}$. Separation of the formulations was tested by centrifuging the sample for 20 minutes at $5000 \mathrm{rpm}$. For further studies, only formulations that are stable have been selected for further study [34]. 


\subsubsection{Robustness to dilution}

DP loaded L-SMEDDS was diluted 50, 100 and 500 times with $0.1 \mathrm{~N} \mathrm{HCl}(\mathrm{pH} 1.2)$ and phosphate buffer $(\mathrm{pH} 7.4)$ for $24 \mathrm{~h}$ at room temperature and examined for any evidence of phase separation or precipitation [35].

\subsubsection{Globule size, polydispersity index and zeta potential}

The SMEDDS formulations $(100 \mu \mathrm{l})$ were diluted in a beaker to $300 \mathrm{ml}$ and combined gently using a glass rod. Particle size analysis (Horiba, Zeta sizer SZ-100 Make and model) was then carried out. Volume size distribution was used to calculate the particle size of the emulsion. All the studies were repeated in triplicate [36].

\subsubsection{Content of DP}

Precisely measured, L-SMEDDS equal to $25 \mathrm{mg}$ DP has been put in $50 \mathrm{ml}$ of the methanol-containing volumetric flask, sonicated for 15-20 minutes to extract the DP. Aliquots $(2 \mathrm{ml})$ were further diluted and UVspectrophotometer was used to measure the absorbance. The DP concentration was measured using the normal calibration curve [37].

\subsubsection{Cloud point determination}

The stable formulation was subjected to cloud point determination. DP-loaded SMEDDS formulation was diluted with $0.1 \mathrm{~N} \mathrm{HCl}$. The water bath was initially maintained at $25^{\circ} \mathrm{C}$ with a gradual increase of temperature at a rate of $5^{\circ} \mathrm{C} / \mathrm{min}$ and the temperature at which cloudiness appeared was recorded as the cloud point [38].

\subsubsection{Drug precipitation study}

The optimized L-SMEDDS formulations loaded with DP were dispersed in $500 \mathrm{ml}$ distilled water (equivalent to $25 \mathrm{mg} \mathrm{DP})$. After completion of the dispersion process, the microemulsion was filtered through whatman filter paper and DP observed by UV visible spectroscopy at $1 \mathrm{~h}$ and $6 \mathrm{~h}$ for any signs of phase separation or drug precipitation [39].

\subsubsection{In vitro drug release studies}

A study on in vitro drug release was performed using $900 \mathrm{ml}$ of buffer $\mathrm{pH} 1.2$ and phosphate buffer pH 7.4 in USP apparatus-I. Baskets were rotated at $100 \mathrm{rpm}$ and held a temperature of $37 \pm 0.5^{\circ} \mathrm{C}$. The DP loaded L-SMEDDS filled in hard gelatin capsules (0 sizes) used in drug release studies and compared the findings to plain DP. Samples $(5 \mathrm{ml})$ were collected at a predetermined time interval; sink condition maintained and the samples were analyzed by UV-spectrophotometer at $290 \mathrm{~nm}$ for DP content [40].

\subsubsection{Ex-vivo intestinal permeability}

Male wistar rats (200-250 g) were sacrificed, the duodenum was removed to study the ex-vivo intestinal permeability. Duodenum was washed thoroughly with cold Ringer to remove adherents. DP loaded L-SMEDDS (diluted upto $5 \mathrm{~mL}$ with distilled water) and plain DP suspension prepared in tyrode filled with duodenum tied at both ends. Tied rat duodenum was placed in a beaker supplemented by aeration containing a tyrode solution. Aliquots $(5 \mathrm{ml})$ were collected at 30 minutes interval, sink condition was maintained and permeated DP was analyzed at $290 \mathrm{~nm}$ by UV-spectrophotometer [41].

\subsection{Formulation of solid SMEDDS}

Hydrophobic carriers aerosil 200 and neusilin US2 were chosen to formulate S-SMEDDS. Chosen carriers were suspended with DP loaded L-SMEDDS and sprayed using a spray dryer (LU 222, Labultima, Mumbai, India). While there are numerous research papers on search engines where S-SMEDDS prepared with L-SMEDDS spray drying with neusilin US2.When we tried at our lab, neusilin US2 blocked the spray dryer nozzle even at the lowest concentration (L-SMEDDS: Neusilin US2, 1:0.5). Thus, spray drying was continued with aerosil while we opted adsorption technique for neusilin US2. S-SMEDDS of DP using neusilin US2 was formulated by the adsorption technique. DP loaded optimized L-SMEDDS were added drop-wise over highly porous neusilin US2 in the ratio of 1:0.50 and 1:0.75 (weight basis). Proper mixing was done after each addition. This resulted in granular mass which further passed through a sieve number 120 to give a free-flowing powder. 
Hydrophobic carrier, aerosil 200 was suspended for 15-20 min at various concentrations in $100 \mathrm{ml}$ distilled water with magnetic stirring at 200-300 rpm. To prepare a suspension DP loaded optimized LSMEDDS are gently dispersed in the above dispersion. Spray-dried the suspension using a lab spray dryer. For the experiments, Box-Behnken experimental designs (BBD) were used of three factors, three levels. Preliminary runs to test the independent variables within the correct range were performed. Temperature (A), feed flow rate (B), and carrier concentration in the feed solution (C) were selected as independent variables. Variables and their levels used in BBD are summerized in Table 5. A total of 15 experimental runs, for the three-level three-factor Box-Behnken experimental design are reported in table 5 .

The dependent variables were droplet size (Y1), and the realistic yield percentage (Y2). The conceptual design goal was to achieve the required quality features. The statistical experiments were designed and assessed using the software Design-Expert ${ }^{\circledR}$ (V. 11, Stat-Ease Inc., Minneapolis, MN, U.S.A.).

All other parameters used were held constant: air pressure $(1.5-2 \mathrm{~kg} / \mathrm{cm} 2)$; aspirator flow rate $(80 \mathrm{Nm} 3 / \mathrm{Hr})$ and vacuum -100 to $-200 \mathrm{mmWC}$ (column water); the powder obtained from the cyclones was collected to determine practical yield. The collected powder was packed in a closed glass container. SSMEDDS prepared for flow properties, dilution efficiency, and in vitro release were evaluated. For DSC, XRD and SEM, in vivo anti-inflammatory behavior in carrageenan-induced animal model [41], and a onemonth stability test $\left(40 \pm 5^{\circ} \mathrm{C}\right.$ and $75 \pm 5$ percent $\left.\mathrm{RH}\right)$, optimized formulation was characterized.

Author contributions: Concept -J.M., S.D.; Design - J.M., A.S., S.D.; Supervision - J.M., S.D.; Resources - DYPIPSR, Pimpri, Pune; Materials - NA, Data Collection and/or Processing - A.S.; Analysis and/or Interpretation - - J.M., A.S., S.D., G.M.; Literature Search - - J.M., A.S., S.D., G.M.; Writing - J.M., A.S., S.D.; Critical Reviews - J.M., A.S., S.D., G.M.

Conflict of interest statement: The authors declared no conflict of interest.

Ethics committe approval: All experimental protocols were performed according to Institute Animal Ethical committee with approval number of DYPIPSR/IAEC/Nov./18-19/P-16 on 29/11/2018.

\section{REFERENCES}

[1] Kovvasu S, Kunamaneni P, Joshi R, Betageri G. Self-emulsifying drug delivery systems and their marketed products: a review. Asian J Pharm. 2019; 13(2): 73-84. [CrossRef]

[2] Pouton C. Formulation of poorly water-soluble drugs for oral administration: physicochemical and physiological issues and the lipid formulation classification system. Eur J Pharm Sci. 2006; 29(3-4): 278-87. [CrossRef]

[3] Agrawal S, Giri T, Tripathi D, Azazuddin, Alexander A. A review on novel therapeutic srategies for the enhancement of solubiltiy for hydrophobic drugs through lipid and surfactant based Self micro emulsifying drug delivery system: A novel approach. Am J Drug Discov Dev. 2012; 2(4): 143-183. [CrossRef]

[4] Shafiq S, Shakeel F, Talegaonkar S, Ahmad F, Khar R, Ali M. Development and bioavailability assessment of ramipril nanoemulsion formulation. Eur J Pharm Biopharm. 2007; 66(2): 227-243. [CrossRef]

[5] Constantinides P. Lipid microemulsions for improving drug dissolution and oral absorption: physical and biopharmaceutical aspects. Pharm Res. 1995; 12(11): 1561-1572. [CrossRef]

[6] Sanghai B, Aggarwal G, HariKumar S. Solid self microemulsifying drug delivery system: a review. J Drug Deliv ther. 2013; 3(3): 168-174. [CrossRef]

[7] Midha K, Nagpal M, Singh G, Aggarwal G. Prospectives of solid self-microemulsifying systems in novel drug delivery. Curr Drug Deliv. 2017; 14(8): 1078-1096. [CrossRef]

[8] Mahore J, Suryawanshi S, Shirolkar S, Deshkar S. Enhancement of percutaneous delivery of dapsone by microemulsion gel. J Young Pharm. 2017; 9(4): 507. [CrossRef]

[9] Legendre D, Muzny C, Swiatlo E. Hansen's disease (leprosy): current and future pharmacotherapy and treatment of disease-related immunologic reactions. Pharmacotherapy. 2012; 32(1): 27-37. [CrossRef]

[10] Bachhav Y, Patravale V. Microemulsion based vaginal gel of fluconazole: formulation, in-vitro and in-vivo evaluation. Int J Pharm. 2009; 365(1-2): 175-179. [CrossRef]

[11] Deshkar SS, Bhalerao SG, Jadhav MS, Shirolkar SV. Formulation and optimization of topical solid lipid nanoparticles based gel of dapsone using design of experiment. Pharm Nanotechnol. 2018; 6(4): 264-75. [CrossRef] 
[12] Garse H, Jagtap P, Kadam V. Solid lipid nanoparticles based gel for topical delivery of antifungal agent. Int J Pharm Sci Res. 2015; 6(8): 3571. [CrossRef]

[13] Lee D, Marasini N, Poudel B, Kim J, Cho H, Moon B, Choi H, Yong C, Kim J. Application of Box-Behnken design in the preparation and optimization of fenofibrate-loaded self-microemulsifying drug delivery system (SMEDDS). J Microencapsulation. 2014; 31(1): 31-40. [CrossRef]

[14] Cho H, Lee D, Marasini N, Poudel B, Kim J, Ramasamy T, Yoo B, Choi H, Yong C, Kim J. Optimization of self microemulsifying drug delivery system for telmisartan using Box-Behnken design and desirability function. J Pharm Pharmacol. 2013; 65(10): 1440-1450. [CrossRef]

[15] Goddeeris C, Coacci J, Van den Mooter G. Correlation between digestion of the lipid phase of smedds and release of the anti-HIV drug UC 781 and the anti-mycotic drug enilconazole from smedds. Eur J Pharm Biopharm. 2007; 66(2): 173-81. [CrossRef]

[16] Zakkula A, Babulal B, Jairam R, Kiran V, Todmal U, Mullangi R. Preparation and optimization of nilotinib selfmicro emulsifying drug delivery systems to enhance oral bioavailability. Drug Dev Ind Pharm. 202; 46(3): 498-504 [CrossRef]

[17] Tadros T, Izquierdo P, Esquena J, Solans C. Formation and stability of nano-emulsions. Adv Colloid Interface Sci. 2004; (108): 303-318. [CrossRef]

[18] Qi X, Qin J, Ma N, Chou X, Wu Z. Solid self-microemulsifying dispersible tablets of celastrol: Formulation development, charaterization and bioavailability evaluation. Int J Pharm. 2014; 472(1-2): 40-7. [CrossRef]

[19] Cheng G, Hu R, Ye L, Wang B, Gui Y, Gao S, Li X, Tang J. Preparation and in vitro/in vivo evaluation of puerarin solid self-microemulsifying drug delivery system by spherical crystallization technique. AAPS PharmSciTech. 2016; 17(6): 1336-46. [CrossRef]

[20] Wei L, Sun P, Nie S, Pan W. Preparation and Evaluation of SEDDS and SMEDDS Containing Carvedilol. Drug Development and Industrial Pharmacy. 2005; 31: 785-794. [CrossRef]

[21] Kommuru T, and Gurley B. Self-emulsifying drug delivery systems (SEDDS) of coenzyme Q10: formulation development and bioavailability assessment. Int J Pharm. 2001; 212: 233-246. [CrossRef]

[22] Levy M, Benita S. Drug release from submicronized o/ w emulsion: a new in vitro kinetic evaluation model. Int J Pharm. 1990; 66: 29-37. [CrossRef]

[23] Borkovec M. From micelles to microemulsion droplets: Size distributions, shape fluctuations, and interfacial tensions. J Chem Phys. 1989; 91: 6268. [CrossRef]

[24] Craig D, Barker S, Banning D, Booth S. An investigation into the mechanisms of self-emulsification using particle size analysis and low frequency dielectric spectroscopy. Int J Pharm. 1995; 114(1): 103-10. [CrossRef]

[25] Chaudhary A, Nagaich U, Gulati N, Sharma VK, Khosa RL, Partapur MU. Enhancement of solubilization and bioavailability of poorly soluble drugs by physical and chemical modifications: A recent review. J Adv Pharm Educ Res. 2012; 2(1): 32-67.

[26] Martins S, Sarmento B, Ferreira D, Souto E. Lipid-based colloidal carriers for peptide and protein deliveryliposomes versus lipid nanoparticles. Int J Nanomedicine. 2007; 2(4): 595.

[27] Bandivadeka M, Pancholi S, Kaul-Ghanekar R, Choudhari A, Koppikar S. Self-microemulsifying smaller molecular volume oil (Capmul MCM) using non-ionic surfactants: a delivery system for poorly water-soluble drug. Drug Dev Ind Pharm. 2012; 38(7): 883-892. [CrossRef]

[28] Deokate U, Shinde N, Bhingare U. Novel approaches for development and characterization of SMEDDS. Int J Curr Pharm Res. 2013; 5(4): 5-12

[29] Date A, Nagarsenker M. Design and evaluation of self-nanoemulsifying drug delivery systems (SNEDDS) for cefpodoxime proxetil. Int J Pharm. 2007; 329(1-2): 166-72. [CrossRef]

[30] Poudel B, Marasini N, Tran T, Choi H, Yong C, Kim J. Formulation, characterization and optimization of valsartan self-microemulsifying drug delivery system using statistical design of experiment. Chem Pharm Bull. 2012; 60(11): 1409-1418. [CrossRef]

[31] Kamisetti RR, Gupta VR. Solubility enhancement of ebastine by self-nanoemulsifying delivery strategy: formulation, optimization and characterization. Int J Pharm Sci Nanotech. 2017; 10(4): 3779-387.

[32] Panapisal V, Charoensri S, Tantituvanont A. Formulation of microemulsion systems for dermal delivery of silymarin. AAPS Pharmscitech. 2012; 13(2): 389-399. [CrossRef] 
[33] Wu X, Xu J, Huang X, Wen C. Self-microemulsifying drug delivery system improves curcumin dissolution and bioavailability. Drug Dev Ind Pharm. 2011; 37(1): 15-23. [CrossRef]

[34] Parmar N, Singla N, Amin S, Kohli K. Study of cosurfactant effect on nanoemulsifying area and development of lercanidipine loaded (SNEDDS) self nanoemulsifying drug delivery system. Colloids Surf B. 2011; 86(2): 327-38. [CrossRef]

[35] Patel A, Shelat P, Lalwani A. Development and optimization of solid self nanoemulsifying drug delivery (SSNEDDS) using D-optimal design for improvement of oral bioavailability of amiodarone hydrochloride. Curr Drug Deliv. 2015; 12(6): 745-60. [CrossRef]

[36] Kang B, Lee J, Chon S, Jeong S, Yuk S, Khang G, Lee H, Cho S. Development of self-microemulsifying drug delivery systems (SMEDDS) for oral bioavailability enhancement of simvastatin in beagle dogs. Int J Pharm. 2004; 274(1-2): 65-73. [CrossRef]

[37] Silva L, Almeida S, Alonso E, Rocha P, Martins F, Freitas L, Taveira S, Cunha-Filho M, Marreto R. Preparation of a solid self-microemulsifying drug delivery system by hot-melt extrusion. Int J Pharm. 2018; 541(1-2): 1-10. [CrossRef]

[38] Patel P, Patel H, Panchal S, Mehta T. Self micro-emulsifying drug delivery system of tacrolimus: formulation, in vitro evaluation and stability studies. Int J Pharm Investig. 2013; 3(2): 95. [CrossRef]

[39] Singh D, Tiwary A, Bedi N. Role of porous carriers in the biopharmaceutical performance of solid SMEDDS of canagliflozin. Recent patents on drug delivery \& formulation. 2018; 12(3): 179-98. [CrossRef]

[40] Monteiro L, Lione V, do Carmo F, do Amaral L, da Silva J, Nasciutti L, Rodrigues C, Castro H, de Sousa V, Cabral L. Development and characterization of a new oral DP nanoemulsion system: permeability and in silico bioavailability studies. Int J Nanomedicine 2012; (7): 5175. [CrossRef]

[41] Dhome A, Deshkar S, Shirolkar S. Gliclazide solid lipid nanoparticles: formulation, optimization and in vitro characterization. Pharmaceutical Resonance. 2018; 1(1): 8-16.

[42] Bhagwat D, Souza J. Formulation and evaluation of solid self micro emulsifying drug delivery system using aerosil 200 as solid carrier. Int J Curr Pharm Res. 2012; 1(12): 414-419. [CrossRef]

This is an open access article which is publicly available on our journal's website under Institutional Repository at http://dspace.marmara.edu.tr. 